\title{
IDENTIFIKASI MEDICATION ERROR PADA RESEP PASIEN POLI INTERNA DI INSTALASI FARMASI RUMAH SAKIT BHAYANGKARA Tk. III MANADO
}

\author{
Tiansi Veren Maalangen ${ }^{1)}$, Gayatri Citraningtyas ${ }^{1)}$, Weny I. Wiyono ${ }^{1)}$ \\ ${ }^{1)}$ Program Studi Farmasi, FMIPA UNSRAT, MANADO
}

\begin{abstract}
Medication Error is every event that can be avoided which can cause or result in improper drug service or harm the patient while the drug is under the supervision of health personnel or patients. The aim of the study was to find out the prevalence of Medication Errors, which occur, in the precscribing phase and the dispensing phase of internal outpatient clinic. This research is a descriptive analysis research with prospective data collection. Study sample is 332 prescriptions of internal outpatient clinic who entered the pharmaceutical installation of Bhayangkara Hospital, Level III, in the period of January 2019. The results showed that there was a Medication Error in both phases. Medication Error that occurs in the prescribing phase includes; no birth date (age) $80.12 \%$, no dosage form $38.85 \%$, no consentration/dosage $27.71 \%$, incomplete prescription of hard drugs $6.32 \%$, can't read prescribing letter $3.01 \%$, incorrect/unclear patient name $1.20 \%$, there is no number of drugs $0.30 \%$ and there are no administration rules $0.30 \%$. Medication Error that occurs in the dispensing phase includes; drug delivery outside the instructions is $8.13 \%$, the drug delivered is less that $1.81 \%$, and writing etiquette is wrong or incomplete $0.30 \%$. Based on the data above, it can be concluded that there is a potensial of Medication Error in the prescribing and dispensing phase at Bhayangkara Hospital, Level III, Manado.
\end{abstract}

Keywords: Medication Error, Prescribing, Dispensing, Clinic Internally Bhayangkara Hospital Tk.III Manado.

\begin{abstract}
ABSTRAK
Medication Error adalah setiap kejadian yang dapat dihindari yang dapat menyebabkan atau berakibat pada pelayanan obat yang tidak tepat atau membahayakan pasien sementara obat berada dalam pengawasan tenaga kesehatan atau pasien. Tujuan penelitian yaitu mengetahui prevalensi Medication Error yang terjadi pada fase prescribing dan fase dispensing pasien rawat jalan poli interna. Penelitian ini merupakan penelitian analisis deskriptif dengan pengumpulan data secara prospektif. Terhadap 332 resep pasien rawat jalan Poli Interna yang masuk di instalasi farmasi Rumah Sakit Bhayangkara Tk.III Manado periode bulan Januari 2019. Hasil penelitian menunjukkan bahwa terjadi Medication Error pada kedua fase tersebut. Medication Error yang terjadi pada Fase prescribing meliputi; tidak ada tanggal lahir (usia) $80.12 \%$, tidak ada bentuk sediaan $38.85 \%$, tidak ada konsentrasi/dosis sediaan $27.71 \%$, tidak lengkap penulisan resep obat keras $6.32 \%$, tulisan resep tidak terbaca $3.01 \%$, salah/tidak jelas nama pasien $1.20 \%$, tidak ada jumlah obat $0.30 \%$ dan tidak ada aturan pakai $0.30 \%$. Medication Error yang terjadi pada Fase dispensing meliputi; pemberian obat diluar instruksi $8.13 \%$, obat yang diserahkan kurang $1.81 \%$, dan penulisan etiket yang salah atau tidak lengkap $0.30 \%$. Berdasarkan data diatas dapat disimpulkan bahwa masih terjadi Medication Error pada fase prescribing dan dispensing di Rumah Sakit Bhayangkara Tk.III Manado.
\end{abstract}

Kata kunci : Medication Error, Prescribing, Dispensing, Poli Interna Rumah Sakit Bhayangkara Tk.III Manado. 


\section{PENDAHULUAN}

Medication Error adalah setiap kejadian yang dapat dihindari yang dapat menyebabkan atau berakibat pada pelayanan obat yang tidak tepat atau membahayakan pasien (NCCMERP, 2016). Medication Error sampai saat ini tetap menjadi salah satu permasalahan kesehatan yang banyak menimbulkan berbagai dampak bagi pasien mulai dari resiko ringan bahkan resiko yang paling parah yaitu menyebabkan suatu kematian (Aronson, 2009). Menurut Peraturan Menteri Kesehatan RI (2014), Kesalahan pengobatan dapat terjadi dalam tiap proses pengobatan, baik dalam proses peresepan (prescribing), pembacaan resep (transcribing), penyiapan hingga penyerahan obat (dispensing), maupun dalam proses penggunaan obat (administration). Kesalahan dalam prescribing dan dispensing merupakan dua hal yang sering terjadi dalam kesalahan pengobatan.

\section{Institute of Medicine USA} memperkirakan Medication Error menjadi penyebab 7000 kematian di USA pertahun (Cahaya N, 2014). Penelitian serupa juga dilakukan oleh Kung et al (2013), di Rumah Sakit Universitas Bern, Switzerland melaporkan sebanyak 288 terjadi Medication Error dari total 24.617 pengobatan yang diberikan pada pasien, di mana sebanyak 29\% dari Medication Error berupa prescribing error, $13 \%$ transcribing error, dan $58 \%$ berupa administration error.

Berdasarkan penelitian Timbongol (2016), yang dilakukan terhadap resep pasien rawat jalan di Poli Interna RSUD Bitung menunjukkan Medication Error yang terjadi pada tahap prescribing yaitu tidak ada bentuk sediaan $74,53 \%$, tidak ada dosis sediaan $20,87 \%$, tidak ada umur pasien $62,87 \%$, tulisan resep tidak terbaca atau tidak jelas $6,50 \%$. Sebuah studi pernah dilakukan terhadap resep dari dokter spesialis anak pada tiga apotek di Kota Manado dan dilakukan evaluasi kelengkapan administratif resep. Berdasarkan 338 resep yang diperiksa, dapat disimpulkan resep tersebut berpotensi terjadinya Medication Error (Mamarimbing, 2012).

Berdasarkan berbagai penelitian di atas serta berdasarkan wawancara dari Rumah Sakit Bhayangkara Tk.III Manado mengatakan, pada tahun 2017 pernah terjadi kejadian Medication Error pada pasien rawat jalan, namun belum sampai dikonsumsi oleh pasien. Peneliti tertarik untuk melakukan penelitian tentang Medication Error pada resep di poli interna Rumah Sakit Bhayangkara Tk. III Manado.

\section{METODOLOGI PENELITIAN}

Penelitian ini dilakukan di instalasi farmasi rawat jalan poli interna Rumah Sakit Bhayangkara Manado, pada bulan Oktober 2018 - April 2019. Jenis penelitian kualitatif yang bersifat deskriptif dengan pengumpulan data secara prospektif. Populasi dalam penelitian ini adalah seluruh resep pasien poli interna di Rumah Sakit Bhayangkara Manado pada bulan Januari 2019. Sampel yang dijadikan subjek penelitian adalah resep pasien poli interna yang masuk di Instalasi Farmasi selama penelitian berlangsung. Sampel penelitian diambil dengan menggunakan metode purposive sampling dengan kriteria inklusi dan ekslusi.

Data dikumpulkan dengan mencatat kejadian Medication Error pada fase prescribing dan fase dispensing dari 
pengamatan resep pasien Rawat Jalan Poli Interna Rumah Sakit Bhayangkara Manado. Data ditabulasi dalam bentuk persentase dari masing-masing bentuk kejadian Medication Error dengan menggunakan grafik.

Analisis data dihitung dalam besaran persentase pada fase kejadian Medication Error. Menurut Sibagariang (2010), penentuan besarnya persentase sebagai berikut:

$$
P=\frac{f}{n} x 100 \%
$$

Keterangan:

$$
\begin{aligned}
\mathrm{P}= & \text { Hasil Persentase } \\
\mathrm{f}= & \text { Frekuensi hasil (kejadian } \\
& \text { Medication Error) }
\end{aligned}
$$

$$
\mathrm{n}=\text { Total seluruh resep }
$$

\section{HASIL DAN PEMBAHASAN HASIL}

Terhadap 332 resep pasien rawat jalan Poli Interna yang masuk di Instalasi Farmasi Rumah Sakit Bhayangkara Tk.III Manado. Sampel diambil berupa resep yang sesuai dengan kriteria inklusi dan kriteria ekslusi kemudian dilakukan analisis deskriptif, maka dapat diketahui persentase Medication Error pada fase prescribing dan fase dispensing.

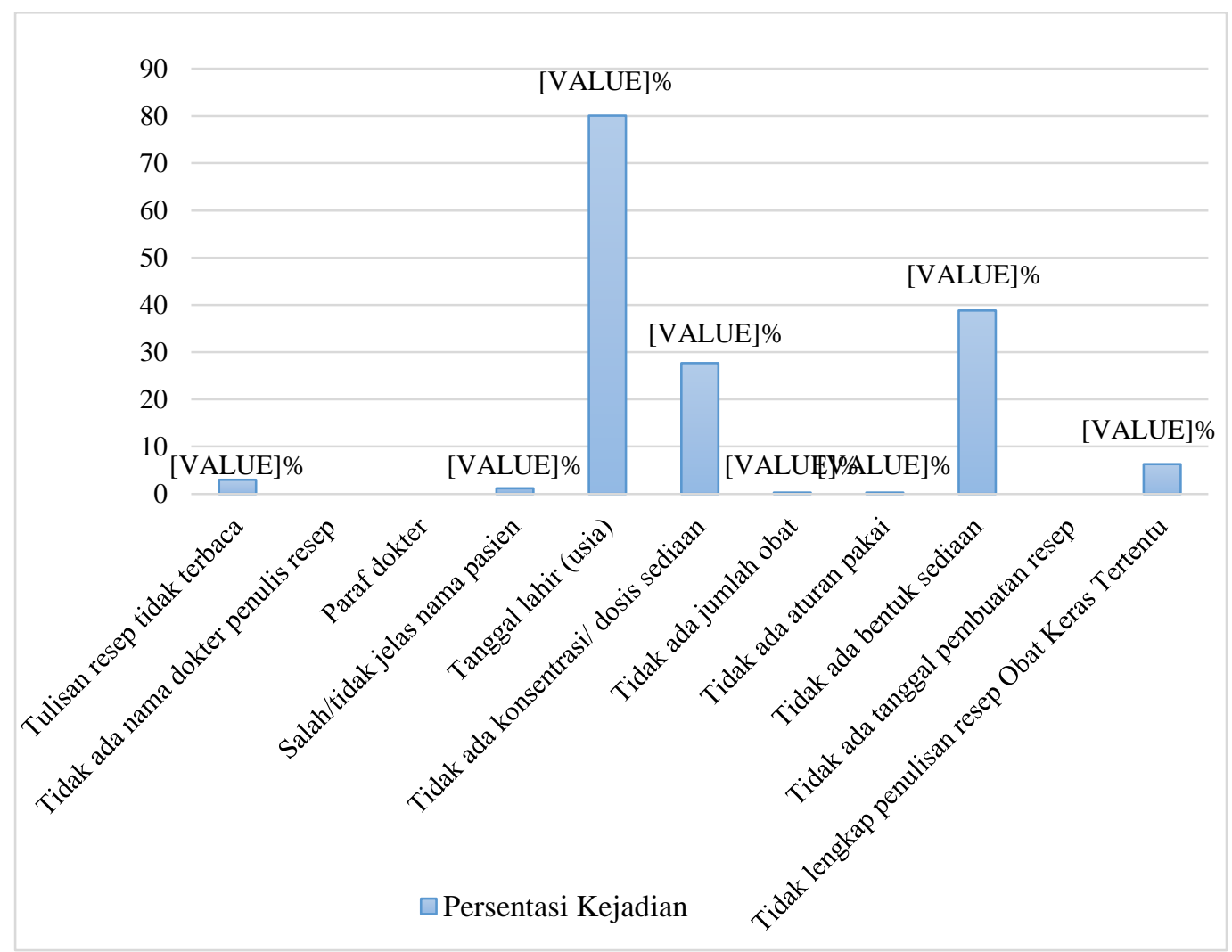

\section{Gambar 1. Grafik Persentase Hasil Penilaian Medication Error pada Fase Prescribing di Poli Interna Rumah Sakit Bhayangkara Tk.III Manado.}

Berdasarkan grafik di atas menunjukan bahwa pada fase prescribing yang berpotensi menimbulkan Medication
Error terbanyak ialah tidak ada tanggal lahir (usia) $80.12 \%$, tidak ada bentuk sediaan $38.85 \%$, tidak ada 
konsentrasi/dosis sediaan $27.71 \%$, tidak lengkap penulisan resep obat keras $6.32 \%$, tulisan resep tidak terbaca $3.01 \%$, salah/tidak jelas nama pasien $1.20 \%$, tidak ada jumlah obat $0.30 \%$ dan tidak ada aturan pakai $0.30 \%$.

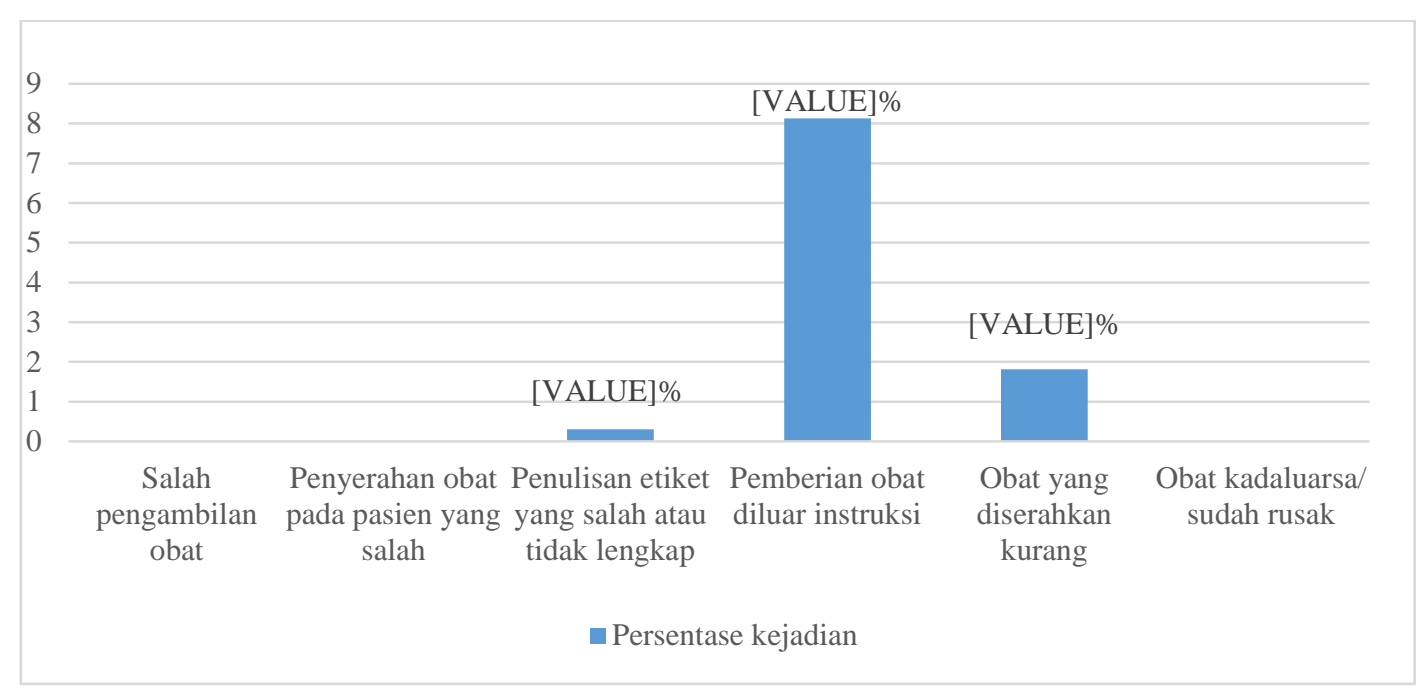

\section{Gambar 2. Grafik Persentase Hasil Penilaian Medication Error pada Fase Dispensing di Poli Interna Rumah Sakit Bhayangkara Tk.III Manado}

Berdasarkan grafik di atas menunjukan bahwa pada fase dispensing yang berpotensi menimbulkan Medication Error terbanyak ialah pemberian obat di luar instruksi $8.13 \%$, obat yang diserahkan kurang $1.81 \%$ dan penulisan etiket yang salah atau tidak lengkap $0.30 \%$.

\section{PEMBAHASAN}

Alur pelayanan resep di Rumah Sakit Bhayangkara dimulai dari konsultasi pasien dengan dokter. Pada tahap ini dokter akan menentukan anamnesis, diagnosis, terapi, serta menuliskan resep. Pada tahapan penulisan resep bisa terjadi prescribing error yang dilakukan oleh dokter. Selanjutnya resep tersebut diberikan kepada pasien dan diserahkan kepada apoteker di Istalasi Farmasi. Apoteker atau asisten apoteker akan melakukan skrining resep atau pemeriksaan resep yang bertujuan untuk mencegah atau mengatasi masalah yang mungkin terjadi pada penulisan resep. Kemudian dilanjutkan pada tahap dispensing, yaitu menyiapkan, meracik, dan memberikan obat serta menjelaskan cara penggunaan obat kepada pasien, pada proses tersebut bisa terjadi dispensing error. Medication Error yang diamati ditulis dalam lembar kerja pengamatan yang akan dinilai berdasarkan formulir yang telah dibuat oleh peneliti.

\section{Identifikasi Medication Error Pada Face Prescribing}

Penelitian ini menggunakan 11 parameter untuk mengidentifikasi Medication Error pada fase prescribing. Hasil penelitian yang dilakukan di rumah sakit Bhayangkara menunjukkan bahwa, masih banyak resep yang tidak mencantumkan tanggal lahir atau usia pasien. Jika tanggal lahir atau usia tidak 
dicantumkan dalam resep maka tidak dapat dijamin ketepatan dosis yang diberikan dan dapat menimbulkan kesalahan pengobatan atau Medication Error (Wibisana, 2014). Bentuk sediaan juga berpengaruh terhadap pasien karena bentuk sediaan obat dipilih demi kenyamanan pasien serta meningkatkan keberhasilan terapi pada saat penggunaan obat oleh pasien (Wiedyaningsih, 2004). Dalam resep tidak ada bentuk sediaan obat terjadi karena sebagian dokter menganggap petugas kefarmasian sudah paham bentuk sediaan obat yang sering diresepkan.

Hasil penelitian menunjukkan bahwa masih banyak penulisan resep yang tidak ada konsentrasi/dosis sediaan. Kesalahan berupa tidak ada konsentrasi/bentuk sediaan ini dapat merugikan pasien karena dapat menyebabkan kegagalan terapi pada saat penggunaan obat oleh pasien. Jika konsentrasi obat lebih kecil dari kebutuhan pasien maka tujuan terapi/ pengobatan yang dijalani tidak tercapai, namun jika dosis obat yang diberikan lebih tinggi maka sangat berbahaya bisa menimbulkan toksisitas bahkan kematian (Susanti, 2013). Berdasarkan hasil penelitian resep obat narkotika dan psikotropika kadang tidak ditulis sesuai dengan kelengkapan resep seperti contoh Codein dan Alprazolam ditulis tidak lengkap yaitu tidak adanya tanda tangan dokter, nomor telepon dokter, serta tidak diberi cap dalam resep tersebut. Berdasarkan observasi peneliti terhadap tenaga kefarmasian tentang penulisan resep yang tidak jelas ataupun tentang penggantian obat, tenaga farmasi selalu mengkonfirmasikan kembali kepada dokter sebelum resep tersebut disiapkan dan diberikan kepada pasien.
Berdasarkan hasil penelitian menunjukkan bahwa masih ada tulisan resep tidak jelas atau tidak terbaca yang menyebabkan adanya hambatan ketika resep tersebut akan diberikan kepada pasien serta berdampak pada tahap selanjutnya, seperti kesalahan pada saat membaca nama obat, konsentrasi obat, aturan pakai obat, jumlah obat, dan kesalahan dalam penyiapan maupun pemberian obat pada pasien (Susanti, 2013). Hasil penelitian di Rumah Sakit menunjukkan bahwa terdapat beberapa resep yang tidak jelas nama pasiennya. Nama pasien penting dalam penulisan resep untuk memastikan kepemilikan resep pasien dan untuk menghidari kesalahan pemberian obat sehingga pengobatan pada pasien dapat tercapai (Anani et al, 2017).

Dalam penulisan resep tidak ada jumlah obat dapat berakibat fatal dalam penggunaan obat karena penulisan jumlah obat sangat dibutuhkan untuk menentukan berapa banyak obat yang dibutuhkan untuk terapi pada pasien tersebut. Jumlah obat juga berhubungan dengan dosis obat yang akan diberikan, dimana dosis itu sendiri adalah jumlah atau ukuran yang diharapkan dapat menghasilkan efek terapi pada fungsi tubuh yang mengalami gangguan (Pernama, 2017). Hasil penelitian menunjukkan bahwa ada salah satu resep yang tidak tercantum aturan pakai. Dalam penulisan resep tidak ada aturan pakai dapat berakibat pada kesalahan dalam penggunaan obat. Aturan pakai pada resep obat sangat penting maka harus ditulis dengan jelas agar tidak terjadi kesalahan dalam penggunaan obat.

Identifikasi Medication Error Pada Fase Dispensing

Sistem penyerahan obat pada
pasien poli interna Rumah Sakit 
Bhayangkara dilakukan oleh apoteker atau asisten apoteker. Kejadian Medication Error yang paling banyak terjadi pada fase ini adalah pemberian obat di luar instruksi. Pemberian obat di luar instruksi dapat berakibat fatal dimana dapat menghasilkan efek terapi yang berbeda serta dapat menyebabkan interaksi obat. Pada Instalasi Farmasi Rumah sakit Bhayangkara jika terdapat obat yang kosong apoteker maupun asisten apoteker selalu mengkonfirmasi kepada dokter apabila obat tersebut ingin diganti. Contoh yaitu obat yang diminta Irbesartan $300 \mathrm{mg}$ tetapi yang diberikan Irbesartan $150 \mathrm{mg}$ hal ini menyebabkan pasien tidak mendapatkan hasil terapi yang sesuai dengan hasil terapi yang diinginkan. Penyusunan obat di instalasi farmasi Rumah Sakit Bhayangkara disusun berdasarkan alfabet serta penyimpanan berdasarkan FIFO (first In First Out), tetapi untuk nama dan tampilan yang hampir sama (LASA/look alike sound alike) tidak diberi tanda, sehingga dapat menyebabkan salah pengambilan obat (Penama, 2017).

Selama penelitian terdapat beberapa kasus kesalahan pada saat pemberian obat, yaitu masih ada obat yang kurang atau tidak diberikan. Kesalahan ini juga terjadi dikarenakan, banyaknya resep yang masuk ke Instalasi Farmasi sehingga mengakibatkan tenaga farmasi kesulitan untuk melakukan konfirmasi kepada dokter untuk mengganti obat tersebut. Selanjutnya dalam penelitian terdapat salah satu resep yang penulisan etiket salah atau tidak lengkap, dimana dalam penulisan etiket tidak ditulis tanggal penulisan resep serta nama pasien. Kesalahan ini terjadi karena banyaknya resep yang masuk ke instalasi farmasi sehingga menyebabkan tenaga farmasi kurang memperhatikan dengan baik dalam menulis etiket. Beban kerja sangat berpengaruh pada pelayanan kefarmasian yang mengakibatkan ketidakseimbangan dalam jumlah resep yang harus dilayani dengan jumlah tenaga farmasi yang berada di Instalasi farmasi (Pernama, 2017). Di instalasi farmasi Rumah sakit Bhayangkara jam kerja setiap tenaga farmasi hanya dua orang dalam satu shift selama 24 jam, sehingga dapat menyebabkan kesalahan dalam pengobatan.

Kesalahan dalam penyerahan obat pada pasien yang salah dan obat kadaluarsa atau obat rusak dapat menyebabkan terjadinya Medication Error yang fatal. Dalam penelitian tidak terdapat kesalahan dalam hal tersebut, dikarenakan setiap penyerahan resep dipanggil untuk dikonfirmasi terlebih dahulu dengan pasien agar tidak terjadi kesalahan. Ruangan Instalasi Farmasi dilengkapi dengan dua pendingin/AC yang masingmasing di letakkan pada ruang tunggu dan ruang peracikan. Obat-obat yang tidak stabil pada suhu rungan disimpan di lemari es sehingga tidak terdapat obat yang kadaluarsa maupun obat rusak. Berdasarkan data di atas, dapat diketahui bahwa masih kerap terjadi Medication Error dalam praktek sehari-hari di instalasi farmasi Rumah Sakit Bhayangkara Manado. Tindakan untuk mencegah terjadinya Medication Error di Rumah Sakit Bhayangkara, yaitu sebaiknya penulis resep harus lebih teliti dalam penulisan resep, juga perlu adanya kerjasama antara apoteker dan dokter, perlu dilakukan edukasi/pembelajaran yang bertujuan untuk mengembangkan pengetahuan. Keterbatasan penelitian hanya sebatas penulisan resep, penyiapan serta pemberian obat kepada pasien. Namun penelitian ini tidak dapat 
mengidentifikasi proses penggunaan obat (fase Administration) pada pasien yang mengalami Medication Error.

\section{KESIMPULAN}

Berdasarkan penelitian yang dilakukan dapat disimpulkan bahwa;

1. Medication Error yang terjadi pada fase prescribing yaitu karena tidak ada tanggal lahir (usia) $80.12 \%$, tidak ada bentuk sediaan $38.85 \%$, tidak ada konsentrasi/dosis sediaan $27.71 \%$, tidak lengkap penulisan resep obat keras $6.32 \%$, tulisan resep tidak terbaca $3.01 \%$, salah/tidak jelas nama pasien $1.20 \%$, tidak ada jumlah obat $0.30 \%$ dan tidak ada aturan pakai $0.30 \%$.

2. Pada fase dispensing yang berpotensi menimbulkan Medication Error yaitu terjadi karena pemberian obat di luar instruksi $8.13 \%$, obat yang diserahkan kurang $1.81 \%$, dan penulisan etiket yang salah atau tidak lengkap $0.30 \%$.

\section{SARAN}

1. Perlu dilakukan penambahan personil tenaga farmasi di Instalasi Farmasi.

2. Kepada dokter, farmasis, dan tenaga kesehatan lainnya untuk lebih memperhatikan hal-hal yang berpotensi untuk menimbulkan Medication Error pada fase prescribing dan fase dispensing.

3. Kepada peneliti selanjutnya agar dilakukan penelitian lebih lanjut mengenai Medication Error pada fase-fase selanjutnya.

\section{DAFTAR PUSTAKA}

Anani., Lizma F., dan Jaka F. 2017. Analisis Prescribing Error Di Beberapa Apotek Wilayah Samarinda
Ulu. Mulawarman Pharmaceuticals Conference. 7(8).

Aronson, J. K. 2009. Medication Errors: Definition and Classification. British Journal of Clinical Pharmacology. 67: 599-604.

Cahaya, N. 2014. Prevalensi Prescribing Error Pada Pasien Rawat Inap Stroke dan Diabetes Mellitus Di Rsud Ulin Banjarmasin. Jurnal Pharmascience. 1(1)

Kung, K., Carrel, T., Wittwer, B., Engberg, S., Zimmermann, N., dan Schwendimann, R. 2013. Medication Errors in A Swiss Cardiovascular Surgery Department: A CrossSectional Study Based on A Novel Medication Error Report Method. Nursing Research and Practice. 4.

Mamarimbing, M. 2012. Evaluasi Kelengkapan Administratif Resep dari Dokter Spesialis Anak pada Tiga Apotek di Kota Manado [Skripsi]. Universitas Sam Ratulangi, Manado.

National Coordination Council for Medication Error Reporting and Prevention (NCCMERP). 2016. http://www.nccmerp.org/aboutmedication-errors $\quad[2$ september 2018].

Peraturan Menteri Kesehatan Republik Indonesia Nomor 58. 2014. Tentang standar pelayanan kefarmasian di Rumah Sakit. Departemen Kesehatan RI, Jakarta.

Pernama, A Maulidan. 2017. Evaluasi Medication Error pada Resep Pasien Diabetes Melitus Tipe II Ditinjau Dari Fase Prescribing, Transcribing, dan Dispensing Di Instalasi Rawat Jalan Salah Satu Rumah Sakit Jakarta Utara [Skripsi]. Fakultas Kedokteran Dan Ilmu Kesehatan Program Studi Farmasi, Jakarta. 
Sibagariang. 2010. Buku Saku Metodologi Penelitian Untuk Mahasiswa Diploma Kesehatan. CV.Trans Info Media, Jakarta.

Susanti I. 2013. Identifikasi Medication Error Pada Fase Prescribing, Transcribing, Dan Dispensing Di Depo Farmasi Rawat Inap Penyakit Dalam Gedung Teratai, Instalasi Farmasi Rsup Fatmawati [Skripsi]. Fakultas Kedokteran Dan Ilmu Kesehatan Program Studi Farmasi, Jakarta.

Timbongol, C. 2016. Identifikasi Kesalahan Pengobatan (Medication Error) pada tahap peresepan (Prescribing) di Poli Interna RSUD Bitung [Skripsi]. FMIPA Unsrat, Manado.

Wibisana, A. 2014. Hubungan Kelengkapan Administratif Resep Dan Polifarmasi Dengan Potensi Medication Error Pada Resep In Health Penyakit Gastritis Di Apotek Sehat Bersama Periode Februari April 2014. Proceeding of the 6th Mulawarman Pharmaceuticals Conferences. 7(8).

Wiedyaningsih, C. 2004. Tinjauan terhadap bentuk sediaan obat: kajian resep-resep di apotek kotamadya Yogyakarta. Jurnal Farmasi Indonesia. 14 (4). 